\title{
From the measles-free status to the current outbreak in Brasil
}

\author{
(D) Marcelo N. Litvoc ${ }^{1}$ \\ DMax Igor Banks F. Lopes ${ }^{1}$
}

1. Departamento de Infectologia do Hospital das Clínicas da Faculdade de Medicina da Universidade de São Paulo, São Paulo, SP, Brasil

In 2016, the American continent was declared measles-free as a result of combined actions by countries in the region and the Pan-American Health Organization (PAHO). The disease caused by the virus of the paramyxoviridae family is characterized by being highly transmissible by respiratory route with the possibility of severe evolution with a risk of death, especially in younger age groups with worse social and nutritional conditions. When the vaccine was introduced in 1963, it became possible to control the transmission of the disease and prevent the free circulation of the virus, which led several regions to achieve the measles-free status ${ }^{1}$. In Brasil, the national immunization program incorporated the vaccine in 1970, modifying the schedule of doses over the decades, according to the epidemiological situation of each period.

Shortly after the Americas were declared measles-free, in July 2017, new cases of the disease were reported in Venezuela, where they started to occur endemically. Following migratory flows, cases were reported in Brasil, in the state of Rondônia, as well as in neighboring countries such as Colombia and Ecuador. In 2018, a total of 11 American countries had already reported cases of measles. At the same time, until August 2018 no sustained endemic transmission of measles had occurred in any of these countries, except in Venezuela. At the time, 3,545 cases had been reported in Venezuela, with 62 deaths, and 1,459 cases, with six deaths, had been reported in ten other countries of the region ${ }^{2}$. The presence of the same strain of measles for 12 consecutive months led to the loss of the measles-free status, which, unfortunately, occurred in mid-2018.
In Brasil, after initial cases were reported in Rondônia, other states in the Northern region started notifying more cases, especially the in Amazonas. In July 2018, Roraima and Amazonas declared a state of emergency for 180 days due to the disease. By the end of 2018, 11 Federated Units had notified around 10,000 cases of measles, with 12 deaths. The local vaccination campaigns, especially in the Northern Region, were effective in controlling the outbreak, which was caused by genotype D8 of the measles virus, the same that circulated in Venezuela.

In March 2019, Brasil lost its measles-free status.

In early April of 2019, new cases of measles began to be reported in São Paulo, and the first autochthonous transmission case was confirmed in early May. The initial cases, in April, were considered as imported and came from the island of Malta (arriving by ship through the port of Santos), Israel, and Norway. The genotype involved in the São Paulo cases is the D8.

The most recent data, from the end of August 2019, accounted for 2,753 confirmed cases, 2,109 discarded, and 15,430 under investigation. The distribution includes 13 Brazilian states (São Paulo, Rio de Janeiro, Pernambuco, Santa Catarina, Federal District, Goiás, Maranhão, Paraná, Rio Grande do Norte, Espírito Santo, Bahia, Sergipe, and Piauí) $)^{3}$. The state of São Paulo accounts for $98.3 \%$ of the confirmed cases, which are distributed through $82.5 \%$ of its municipalities, but mostly in the capital. The same state recorded three deaths in patients with no history of vaccination (two children under the age of 1 year and an adult of 42 years $)^{4}$. 
This latest outbreak leads to important reflections on its causes. There is no doubt that among them, is related to low vaccination coverage. It is recommended that all individuals between the age of 15 months and 29 years receive at least two doses of the vaccine. In recent years, Brasil has registered rates below the 95\% coverage target in children. Added to this fact, we have an enormous contingent of adults, especially younger ones, with inadequate immunization due to changes in the vaccination schedule, causing many to have taken only one dose of the vaccine. The dismantling of basic healthcare actions due to the crisis in the country, as well as the increase of anti-vaxxer groups in social media who feed of fraudulent information and untruthful content, contribute to the low coverage in children. It is also known that the average neutralizing antibodies titers in the population have been falling, associated with measles control. This has caused some researchers to discuss the need for a third dose of the vaccine after 15 months of age.
Despite the controversy, all countries that have reached measles-free status did so through consistent immunization campaigns in an attempt to ensure two doses for the entire population ${ }^{5}$. Programmatic and advertising strategies to raise population awareness are key so that we can, once again, become a measles-free country. However, if other countries are not successful as well, the emergence of new outbreaks will always be a reality.

\section{REFERENCES}

1. Strebel, PM, M.B et al. Measles. N Engl | Med 2019; 381:349-357. July 25, 2019.

2. OPAS Brasil - Sarampo. https://www.paho.org/bra/index.php?option=com content\&view=article\&id=5633:folha-informativa-sarampo\&ltemid $=1060$

3. Boletim Epidemiológico 19. Secretaria de Vigilância em Saúde/Ministério da Saúde. Volume 50, Agosto 2019. https://portalarquivos2.saude.gov.br/ images/pdf/2019/agosto/28/BE-2019-24-Sarampo-28ago19-prelo.pdf

4. Boletim Epidemiológico VOL I número 5, 2019. Centro de vigilância epidemiológica do Estado de São Paulo. http://www.saude.sp.gov.br/ resources/cve-centro-de-vigilancia-epidemiologica/areas-de-vigilancia/ doencas-de-transmissao-respiratoria/sindrome-da-rubeola-congenita-src/ doc/2019/sarampo19_5bolepid3108.pdf

5. Paules Cl, Marston HD, Fauci AS. Measles in 2019-Going Backward. N Engl J Med 2019;380:2185-2187. 